\title{
Experimental Measurement of Dynamic Forces Generated during Short-Duration Contacts: Application to Blade-Casing Interactions in Aircraft Engines
}

\author{
M. Cuny $\cdot$ S. Philippon $\cdot$ P. Chevrier $\cdot$ F. Garcin
}

\begin{abstract}
The main purpose of this paper is to present an experimental set-up dedicated to the study of high speed interactions such as those occurring between the rotating blade and the casing of an aircraft engine compressor. A simplified approach of rotor/stator interaction was experimentally simulated for ranges of velocities and interaction depths varying from $60 \mathrm{~m} / \mathrm{s}$ to $270 \mathrm{~m} / \mathrm{s}$ and from $0.13 \mathrm{~mm}$ to $0.35 \mathrm{~mm}$ respectively. Only high speed orthogonal contact were studied. The device was made up of a ballistic bench projecting a sample of abradable material (M601) against an instrumented tool (Steel 42CrMo4) representing the simplified blade shape. In order to increase significantly the measurement system bandwidth and to measure accurately the high speed interaction forces, a correction method based on the principle of modal analysis was developed and successfully employed. This work provides new experimental data regarding the material behavior of M601 in high speed orthogonal cutting conditions. They were in good agreement with those already observed in the literature for velocities up to $100 \mathrm{~m} / \mathrm{s}$. These new results showed the non-linear increase of the mean interaction force with the velocity and incursion depth for the large range of velocities considered in this present work. Post-experiment observations gave evidence of two wear mechanisms: cutting and plastic deformation.
\end{abstract}

Keywords Experimental set-up · High speed interaction · Orthogonal cutting $\cdot$ Abradable $\cdot$ Dynamic force measurement

\section{Nomenclature}

$\Delta T_{i} \quad$ Interaction duration [s]

$\Delta T_{t d} \quad$ Duration of tension drop observed on diode signal [s]

$F_{m} \quad$ Mean Interaction force [N]

$L_{p} \quad$ Projectile length [mm]

$t_{1} \quad$ Mean incursion depth [mm]

$t_{1 t} \quad$ Theoretical incursion depth [mm]

$\Delta t_{1} \quad$ Incursion depth variation during the interaction [mm]

$V_{i} \quad$ Mean interaction velocity calculated by analysing laser diode signal $[\mathrm{m} / \mathrm{s}]$

$V_{\max } \quad$ Maximum interaction velocity calculated by analysing laser diode signal $[\mathrm{m} / \mathrm{s}]$

$V_{M F R} \quad$ Mean interaction velocity calculated by analysing force recordingl $[\mathrm{m} / \mathrm{s}]$

$V_{\min } \quad$ Minimum interaction velocity calculated by analysing laser diode signall $[\mathrm{m} / \mathrm{s}]$

$\gamma^{2} \quad$ Coherence

$G_{I I} \quad$ Input auto-spectrum $\left[N_{2}\right]$

$G_{I O} \quad$ Input-response cross-spectrum [VN]

$G_{O I} \quad$ Response-input cross-spectrum [VN]

$G_{O O} \quad$ Response auto-spectrum [ $\left.V_{2}\right]$

$H_{1} \quad$ First estimation of the frequency response function $[\mathrm{V} / \mathrm{N}]$

$\mathrm{H}_{2}$ Second estimation of the frequency response function $[\mathrm{V} / \mathrm{N}]$

$[H(j \omega)] \quad$ Correction matrix [N/V] 


\begin{tabular}{|c|c|}
\hline$\{I(j \omega)\}$ & $\begin{array}{l}\text { Vector of the Fourier transformed input signals } \\
\text { of forces imposed on the structure } \mathrm{i}(\mathrm{t})[\mathrm{N}]\end{array}$ \\
\hline$\{i(t)\}$ & Input $[\mathrm{N}]$ \\
\hline$I_{a}(j \omega)$ & $\begin{array}{l}\text { Fourier transformed input signal of axial force } \\
\text { imposed on the tool tip [N] }\end{array}$ \\
\hline$\{o(t)\}$ & Output [V] \\
\hline$\{O(j \omega)\}$ & $\begin{array}{l}\text { Vector of the Fourier transformed output signals } \\
\text { delivered by the sensors o(t) }[\mathrm{V}]\end{array}$ \\
\hline$O_{g}(j \omega)$ & $\begin{array}{l}\text { Fourier transformed output signal delivered by } \\
\text { the gauge }[\mathrm{V}]\end{array}$ \\
\hline$O_{p}(j \omega)$ & $\begin{array}{l}\text { Fourier transformed output signal delivered by } \\
\text { the piezoelectric sensor }[\mathrm{V}]\end{array}$ \\
\hline$[T(j \omega)]$ & Transmissibility matrix $[\mathrm{V} / \mathrm{N}]$ \\
\hline$T_{g}(j \omega)$ & $\begin{array}{l}\text { Frequency response function of the strain gauge } \\
\text { [V/N] }\end{array}$ \\
\hline$T_{p}(j \omega)$ & $\begin{array}{l}\text { Frequency response function of the piezoelectric } \\
\text { sensor }[\mathrm{V} / \mathrm{N}]\end{array}$ \\
\hline$[A]^{H}$ & Hermitian transpose of matrix $[\mathrm{A}]$ \\
\hline & Arithmetic mean \\
\hline $\bar{A}$ & Conjugate of a complex number $\mathrm{A}$ \\
\hline$F F T$ & Fast Fourier Transform \\
\hline$F R F$ & Frequency Response Function \\
\hline$L B F$ & Located Frequency Band \\
\hline
\end{tabular}

\section{Introduction}

Increasing efficiency and reducing fuel consumption of aircraft engines require optimization of the clearance between the rotating parts (blades) and the engine case [1]. To achieve reduced clearance without endangering the blading, abradable seals are deposited inside the casing of the different engine stages. This type of coating was designed to wear out in case of contact with the blade tip [2,3] and to thermally insulate the engine casing.

The abradable seals present in the low-pressure compressor stage are generally composed of metal phase and self-lubricating non-metal phase with high porosity [4]. This material, deposited by Atmospheric Plasma Spraying (APS), is known for its good balance between erosion resistance and abradability $[5,6]$ as well as its simple manufacturing process and good sealing effectiveness. In case of contact with the blade tip, it produces fine particles which can be safely ingested by the engine and generates a smooth new surface which is beneficial to the aerodynamics properties.

However, important thermal and mechanical solicitations undergone by the turbomachines, particularly during transient states, lead to high speed interactions between the moving parts and the casing. These interactions can not be avoided in the case of reduced clearance. They have strong consequences on the blade vibratory behavior and may rapidly cause damages to the blading. Thus, characterization and understanding of the different phenomena which take place during interactions are essential to prevent premature wear or failure of the blading and to increase the reliability and service life of engines.

From a phenomenological point of view, wear mechanisms occurring during interaction were identified by Borel [7] and can be separated in two categories: mechanisms occurring without contact (erosion, corrosion and oxidation) and those occurring with contact (cutting, deformation, adhesive transfer, melting and tribo-oxidation). The mechanisms of the first category are undesirable because they increase the clearance between the blading and the seals and therefore decrease engine efficiency. They can be detected when the roughness, the chemistry or the color of the seal surface changes. As for the mechanisms of the second category, deformation appears when the blade plastically deforms the abradable material, smearing the non-metal phase on the metal phase. It can lead to unwanted densification of the material and creates a striated surface. These phenomena are prejudicial to the aerodynamic airtightness and to the abradability. Adhesive transfer corresponds to the transfer of material from the blade onto the seal and reciprocally. Melting produces a hard layer on the abradable seals. Adhesive transfer and melting affect the behavior of the abradable seal and can damage the blading. They should be avoided. On the contrary, the cutting mechanism is the only desirable abradable seal wear process: the blade acts like a cutting tool. This interaction leads to a brittle rupture of the abradable material without damaging the blade tip and generates a very smooth and shiny surface particularly favorable to aerodynamic properties.

From a quantitative point of view, the basic mechanical properties of abradable material are poorly known. These materials are highly anisotropic and a have layered structure resulting from successive deposits of molten/ semi-molten powder. Their mechanical properties are strongly influenced by the shape of these individual deposits, by interactions between the coating and the substrate, and between the different layers. Moreover, a majority of mechanical testing on coatings provides results on the couple coating/substrate. However, quasi-static tensile tests realized by Johnston and Evans [8] on self-supporting freestanding abradable specimens sprayed on dissolvable molds show that the materials have plastic behavior without elastic response. Mechanical and thermal properties of abradable materials are also estimated analytically thanks to a finite element modeling built on analysis of micro-structure $[9,10]$.

As for the rotor/stator interaction phenomenon understanding, a first approach consists in studying the property of abradable material to wear out easily. The abradability is experimentally tested thanks to rub test machines allowing a large range of interaction speed $(<400 \mathrm{~m} / \mathrm{s})$ and temperature $\left(<500^{\circ} \mathrm{C}\right)[11-13]$. However this type of experiments 
is mainly performed to compared abradable materials in order to optimize manufacturing process, to establish wear maps and for phenomenological studies. It does not provide information on the interaction forces applied on the blade tip nor allows to create wear laws. More precisely, it does not provide data suitable to calibrate and validate analytical or numerical models of the blade-casing contact or the abradable materials behavior under dynamical conditions. And these models are essential to optimise the design of new aircraft engines.

From this perspective, two other approaches seem more appropriate. The first one investigates the wear process by means of dry friction experiments. For instance, Yi et al. [14] give experimental values of the friction coefficient for different normal loads but for a low sliding velocity $(\mathrm{V}=$ $0.377 \mathrm{~m} / \mathrm{s}$ ) much inferior to those of compressor blade tips. The authors also establish an inverse correlation between the abradability of a given abradable material and its hardness. However, they also show that the hardness alone can not be consider as a criterion of abradability since the abradability varies from one material to another regardless of their hardness.

The second approach considers the blade to be a complex cutting tool. In this way, orthogonal cutting of abradable coating by titanium tools was studied by Sutter et al. [15] for various interaction speeds ( from $10 \mathrm{~m} / \mathrm{s}$ to $107 \mathrm{~m} / \mathrm{s}$ ), incursion depths (from $0.05 \mathrm{~mm}$ to $0.5 \mathrm{~mm}$ ) and radii of the tool edge (from $0.001 \mathrm{~mm}$ to $0.03 \mathrm{~mm}$ ). They show that mean interaction force increases when speed, incursion depth and radius of the tool edge increase and can be defined as the sum of two forces: a component force induced by friction and another one generated by the cutting interaction process. To generate high speed interaction, various technique are used. Their performances are very different in terms of range of interaction speed, incursion depth, materials involved, and duration of measurement. For the most part, they use machine tools, particularly those designed to study high speed machining (turning, milling, drilling) of metal. Interaction speeds are only limited by the capacity of the machine tool (up to $160 \mathrm{~m} / \mathrm{s}$ in high speed turning [16]). But they generate long duration processes while the rotor/stator contact lasts only a few microseconds. Hydraulic high speed tensile testing machines are also used to generate shortduration contacts $[17,18]$ but their performances in terms of interaction velocity are limited $(<5 \mathrm{~m} / \mathrm{s})$. We chose to use a ballistic bench which allow to generate a short and unique interaction and to obtain a large range of interaction speed (from $3 \mathrm{~m} / \mathrm{s}$ to $600 \mathrm{~m} / \mathrm{s}$ ) [19-24].

Accurate measurement of interaction force under dynamic conditions is difficult as well and requires dynamometers with a high bandwidth. The scientific literature presents a large range of measurement technologies, such as optical systems [25], load cells [26, 27], strain gauges [28-34] sometimes associated with accelerometers [35], and piezoelectric sensors [36]. However, these dynamometers remain limited by their bandwidth (varying between $130 \mathrm{~Hz}$ and $2,35 \mathrm{kHz}$ ). That is why various signal correction methods, principally based on modal analysis, has been developed and are implemented $[36,37]$ to reduce the parasitic phenomena induced by the dynamic behavior of the sensor.

To sum up, the understanding of phenomena occurring during rotor/stator interactions in aircraft engines offers potential for the improvement of their efficiency and reduce their fuel consumption. Aircraft engineering requires numerical simulation tools to optimize design and performance of new engines and to increase their reliability and service life. But models on which these numerical simulation tools are built need to be validated by experimental data. However these data are not easily accessible by standard experimental devices because of the complexity of interactions and the extreme conditions in which they occur. In this paper, a new device is described and adapted to a ballistic bench where interaction velocities can reach up to $500 \mathrm{~m} / \mathrm{s}$. A set of experiments were carried out to investigate the orthogonal cutting process for a couple of materials composed of abradable material M601 and steel $42 \mathrm{MoCr} 4$. The velocities and forces of the interactions as well as the incursion depths were measured. A dynamic correction method based on the modal analysis principle was successfully applied. New interesting experimental data, meant to be used to calibrate and validate numerical models of the abradable material and to optimize the design of the blades, are reported for ranges of velocities and interaction depths varying from $60 \mathrm{~m} / \mathrm{s}$ to $270 \mathrm{~m} / \mathrm{s}$ and from $0.13 \mathrm{~mm}$ to $0.35 \mathrm{~mm}$ respectively. It appears that the mean interaction force increased in a non-linear way as a function of the interaction velocity and the incursion depth. Postexperiment observations highlighted the presence of two wear mechanisms identified by Borel [7]: cutting and plastic deformation.

\section{The Experimental Set-Up}

\section{Experimental Set-Up Description}

Interaction between the blade and the abradable coating was experimentally simulated by projecting a sample of abradable material against a tool representing the blade tip by means of a ballistic bench (Fig. 1(a)). The propulsion device [24] was designed to reach extreme velocity up to $500 \mathrm{~m} / \mathrm{s}$ corresponding approximately to the tangential velocity of the blade in the first compressor stage. However, for this work, the projectile velocity was limited to $300 \mathrm{~m} / \mathrm{s}$ to 
(a)

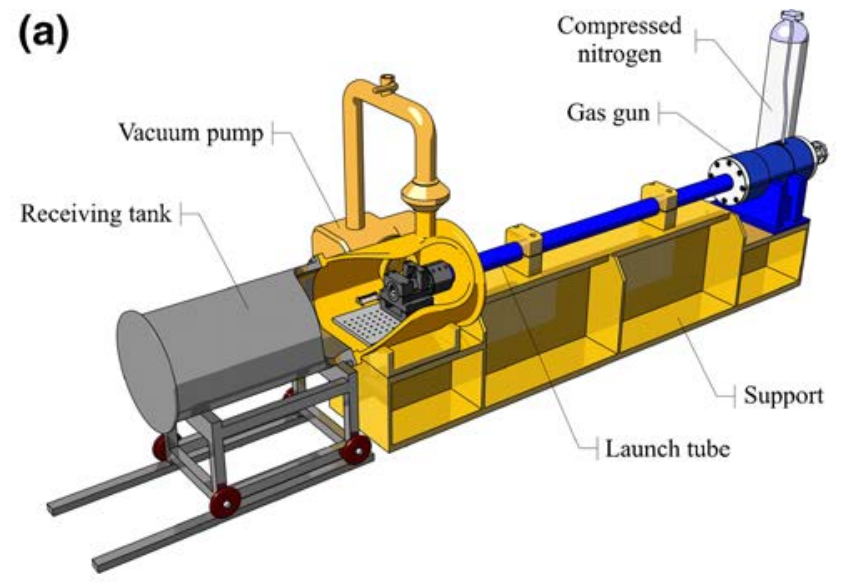

(b)

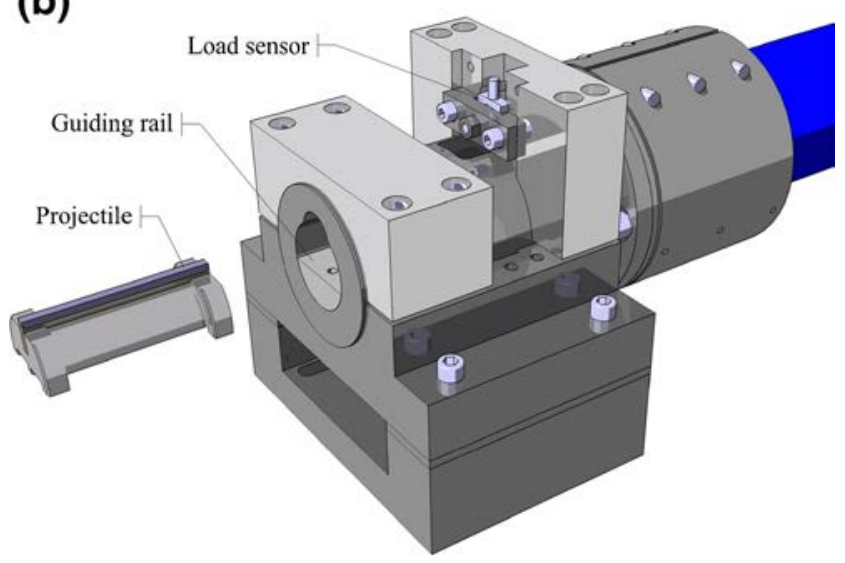

Fig. 1 Experimental set-up. (a) Ballistic bench. (b) Measurement system

preserved some sensitive part of the device, especially the guiding system (launch tube and rail). The device is mainly made of a pneumatic gun using the sudden expansion of compressed nitrogen to launch a semi-cylindrical projectile made of aluminum alloy. This projectile (Fig. 2) supports a sample of abradable material. It is guided along a launch tube and impacts an instrumented tool generating a short interaction. This instrumented tool which will be referred in this paper as the blade. After interaction, a shock absorber, placed in the receiving tank, captures the projectile without damaging the sample of abradable material in order to carry out post-experiment analysis. The experiments are performed under vacuum conditions to minimize blast phenomena perturbing the measurement before and during the interaction process.

\section{Interaction Force Measurement}

The axial force generated during the interaction was measured in the same time by a piezoelectric force sensor (PCB Piezotronic 260A01) connected to an ICP signal conditioner

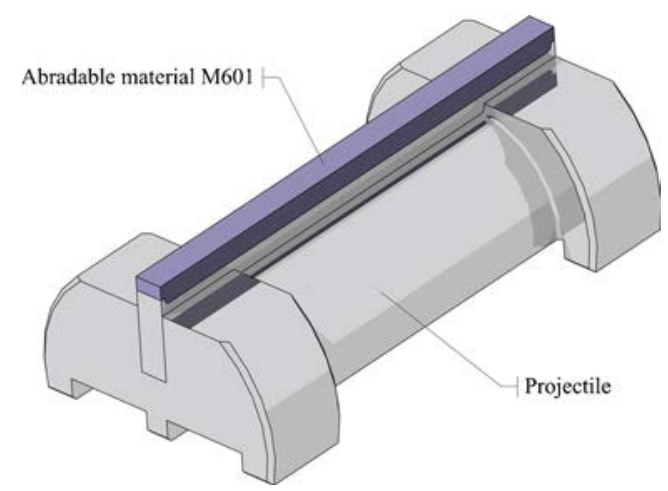

Fig. 2 Projectile and the sample covered with abradable material M601

and a strain gauge glued onto the blade (Fig. 3), connected to a Wheatstone bridge in a quarter-bridge configuration. Both signals of the strain gauge and the piezoelectric force sensor were simultaneously recorded by a computer equipped with an acquisition card with a large bandwidth $(0$ to $480 \mathrm{kHz}$, Fig. 4).

The blade shape and the position of the strain gauge were determined by means of numerical simulations performed with a finite element code (Abaqus ${ }^{\circledR}$, Fig. 5). A compromise between sensitivity and stiffness had to be found to maximize the sensor bandwidth as well as to limit the blade edge displacement and the influence of its dynamic behavior. Eventually, a static calibration was performed to find sensitivities of the measurements by the strain gauge $(0.31 \mathrm{mV} / \mathrm{N})$ and the piezoelectric force sensor $(7.3 \mathrm{mV} / \mathrm{N})$.

\section{Interaction Velocity Measurement}

The projectile velocity during the interaction process is controlled by adjusting the gas pressure. It was precisely calculated in two different ways thanks to the signals recorded during cutting tests (Fig. 6). First, three laser

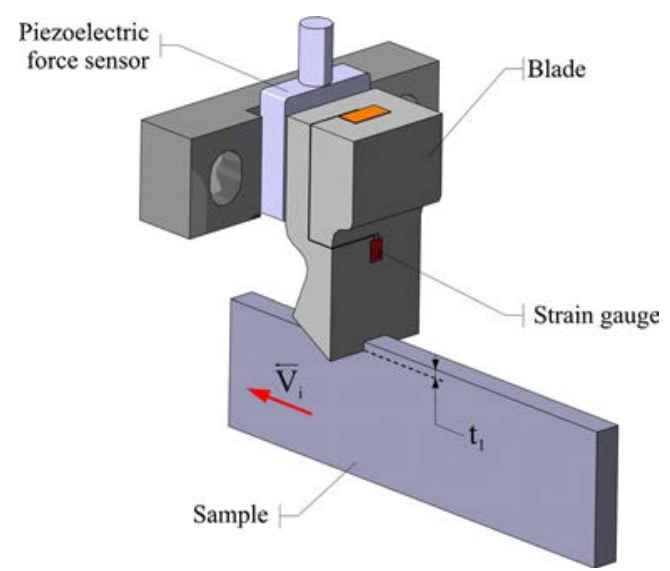

Fig. 3 Schematic description of the interaction process 


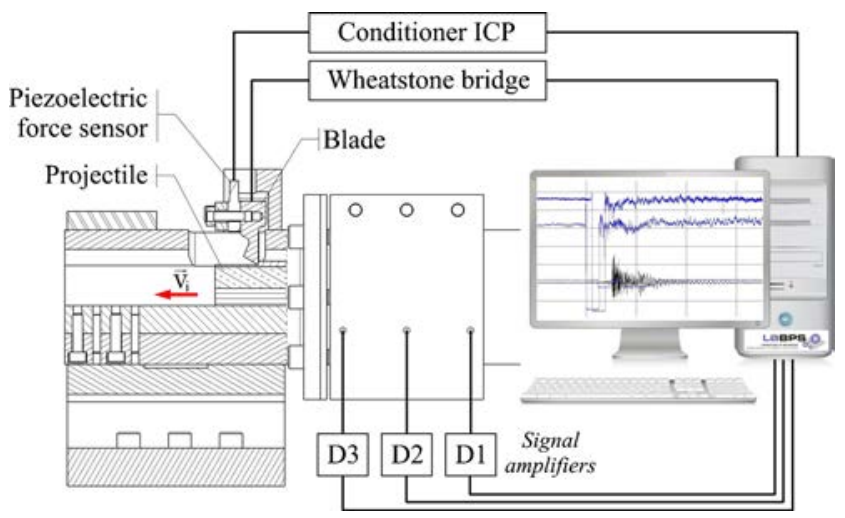

Fig. 4 Data acquisition system of the experimental set-up

diodes, placed at the launch tube exit and spaced with a known distance, allowed to measure interaction velocity at few instants before and during the interaction and to calculate mean interaction velocity $V_{i}$. The measuring accuracy of this method slightly increased with the interaction speed. Indeed, the voltage drops observed on diodes signals, when the projectile cut the laser beams off, had a logically shorter duration $\Delta T_{t d}$ and the relative error committed during interaction velocity calculation decreased in the case of high projectile velocity (Table 1). The analysis of the laser diodes signals and the calculation of interaction velocity at various instants before and during interactions underlined that the velocity variations were insignificant regarding the absolute measuring error. So the sample velocity was assumed to be constant during the interaction process.

The second method consisted in analyzing the force sensors recordings. Assuming a constant velocity of the projectile during the process and knowing precisely its length $L_{p}$, the value of the velocity $V_{M F R}$ was given by the ratio of length $L_{p}$ to duration of interaction $\Delta T_{i}$. The main difficulty of this method consisted in determining precisely the duration of the interaction on the force sensors raw signals. The piezoelectric force sensor recordings were too dynamically perturbed to be used for that task. One the other hand,

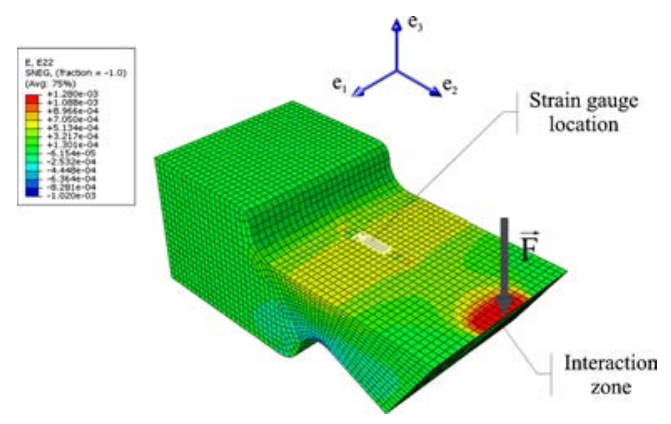

Fig. 5 Strain gauge location on the blade

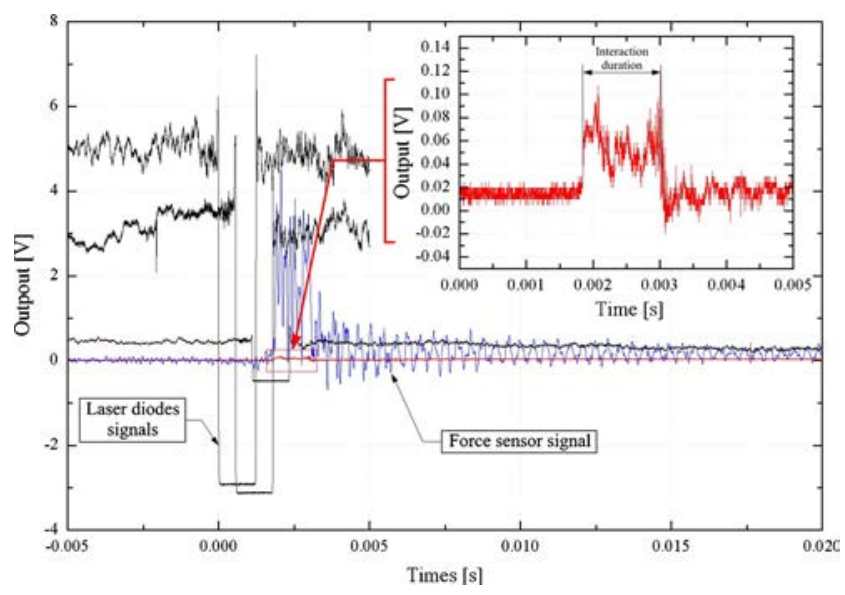

Fig. 6 Typical raw signals obtained during orthogonal cutting experiment. Sample M02-Interaction speed: $90 \mathrm{~m} / \mathrm{s}-$ Mean incursion depth: $0.26 \mathrm{~mm}$

the strain gauge signals allowed to calculate mean interaction velocity in three experimental cases. Nonetheless, the results concerning the mean interaction velocity given by both methods (diode laser signal analysis and strain gauge recordings analysis) for these three cases (M01, M02 and M05) were of the same order. They confirmed that the velocity was constant during interactions and validated the first velocity measurement method.

\section{Incursion Depth Measurement}

Adjust and control the incursion depth required to master the projectile position in the launch tube during the interaction. In order to do that, a semi-cylindrical rail was rigidly fixed in the launch tube to insure a precise guiding of the projectile. To verify the perfect alignment of the different guiding parts as well as the good accuracy of the tolerance of their geometry, validation tests involving launching projectiles without sample were carried out. Indeed, geometrical tolerances and surface roughness of the guiding parts had to be very accurate to ensure precise guiding of the projectile and a repeatable and quasi-constant incursion depth during interaction process. But the slight misalignments of the guiding parts can lead to shocks during the accelerating stage of the projectile. These shocks generated elastic waves transmitted through the device to the force sensors which created perturbations in force measurement. These tests permitted to adjust the device. They eventually showed that alignment was good enough for measuring only force generated during the interaction process without being perturbed by dynamic phenomena occurring when the projectile is sliding through the device (shocks, parasitical contacts due to micrometric variation of the launch tube diameter, etc). 
Table 1 Interaction velocity comparison

\begin{tabular}{llllllll}
\hline Sample & Force recording & \multicolumn{2}{l}{ Laser diode measuring method } \\
\cline { 3 - 8 } & \begin{tabular}{lllllll}
$V_{M F R}$ \\
\cline { 3 - 7 }
\end{tabular} & $\begin{array}{l}V_{i} \\
{[\mathrm{~m} / \mathrm{s}]}\end{array}$ & $\begin{array}{l}V_{\text {min }} \\
{[\mathrm{m} / \mathrm{s}]}\end{array}$ & $\begin{array}{l}V_{\max } \\
{[\mathrm{m} / \mathrm{s}]}\end{array}$ & $\begin{array}{l}\Delta T_{t d} \\
{[\mu \mathrm{s}]}\end{array}$ & $\begin{array}{l}\text { Absolute error } \\
{[\mathrm{m} / \mathrm{s}]}\end{array}$ & $\begin{array}{l}\text { Relative error } \\
{[\%]}\end{array}$ \\
\hline M01 & 61 & 61.3 & 61.1 & 61.5 & 20 & 1.50 & 2.45 \\
M02 & 88 & 89.5 & 88.3 & 89.4 & 14 & 2.25 & 2.52 \\
M03 & $\backslash$ & 90.5 & 90.3 & 90.6 & 13 & 2.12 & 2.35 \\
M04 & $\backslash$ & 117.5 & 116.8 & 117.1 & 10 & 2.75 & 2.34 \\
M05 & 154 & 152.6 & 151.1 & 152.4 & 7 & 3.26 & 2.14 \\
M06 & $\backslash$ & 190.8 & 190.1 & 190.8 & 5 & 3.64 & 1.91 \\
M07 & $\backslash$ & 227.5 & 225.2 & 226.8 & 4 & 4.10 & 1.80 \\
M08 & $\backslash$ & 228.0 & 227.3 & 228.3 & 4 & 4.16 & 1.83 \\
M09 & $\backslash$ & 269.4 & 268.8 & 270.3 & 3 & 4.35 & 1.61 \\
\hline
\end{tabular}

The incursion depth $t_{1}$ was set up before each experiment by adjusting the relative position of the blade from the upper face of the sample. The sample, mounted on the projectile, was machined in order to impose a known distance between the upper face of the sample and the sliding face of the projectile using this last one as a reference. The blade was positioned precisely with a standard piece placed on the guiding rail. Then the theoretical incursion depth $t_{1 t}$ was obtained by the difference between the sample upper surface height and the reference piece height. The real experimental incursion depth was calculated in ten points of the sample regularly spaced comparing the sample upper face height before and after interaction.

For all experiments presented in this paper, the theoretical incursion depth was set to $0.2 \mathrm{~mm}$. However, as shown in Table 4, mean incursion depth $t_{1}$ varied between $0.12 \mathrm{~mm}$ and $0.18 \mathrm{~mm}$ for the samples made of polycarbonate and between $0.13 \mathrm{~mm}$ and $0.35 \mathrm{~mm}$ for the M601 samples. Note that during interaction, the incursion depth was not constant. Its variation $\Delta t_{1}$ fluctuated between $0.032 \mathrm{~mm}$ and $0.048 \mathrm{~mm}$ for the samples made of polycarbonate and between $0.022 \mathrm{~mm}$ and $0.069 \mathrm{~mm}$ for the samples made of M601. Both these variations could be explained by error committed during the sample preparation, the positioning of the blade, the experimental incursion depth measurement and the dynamic behaviors of the blade, of the sample and of the projectile. Nevertheless, it is interesting to note that these variations were lower for the polycarbonate than for the M601. It leads to think that the material behavior of the sample, particularly the mechanical properties could have an influence on the cutting process, the blade tip displacement and the sample roughness after the experiment. This could partially explain the variations of incursion depth around the theoretical value and during interaction.

\section{Interaction Force Correction}

\section{Sensors Dynamic Behavior}

Traditionally, sensors dedicated to dynamic measurement are built as rigid as possible to obtain the highest first mode frequency and the largest bandwidth [33]. Indeed, maximal frequencies excited by mechanical phenomena have to be inferior to the upper limit of the sensor bandwidth to ensure a precise force measurement. The high frequency noise and the vibratory behavior of the sensor are filtered off by applying a low pass filter with a cut-off frequency corresponding to the upper limit of the bandwidth. In this case, a static calibration is sufficient and well-adapted. In this work, the dynamic response of the sensors was investigated by means of pulse tests to determine their bandwidth. The tip of the blade was excited by using an impact ram and the excitation force was measured by a piezoelectric force sensor (PCB Piezotronic 208C02), see Fig. 7. The input (excitation force imposed by the ram) and the outputs (forces measured by piezoelectric force sensor PCB Piezotronic 260A01 and by the strain gauge) were recorded simultaneously. Then, modal analysis was performed to calculate frequency response functions (FRFs, equations (2) and (3)) and the bandwidth was defined when the amplitude of the FRFs exceeded $\pm 3 \mathrm{~dB}$, see Fig. 8 .

These experiments showed that the device bandwidth was inferior to $2 \mathrm{kHz}$, therefore it was not sufficient to accurately measure interaction forces such as those generated during high speed cutting. Indeed, the maximum frequency contained in the studied phenomenon was estimated to be inferior to $10 \mathrm{kHz}$ according to the interaction velocity and duration. Nevertheless, the necessary bandwidth is not obtainable in practice. In fact, if sensors can reach this bandwidth when they are tested alone, it is very difficult 


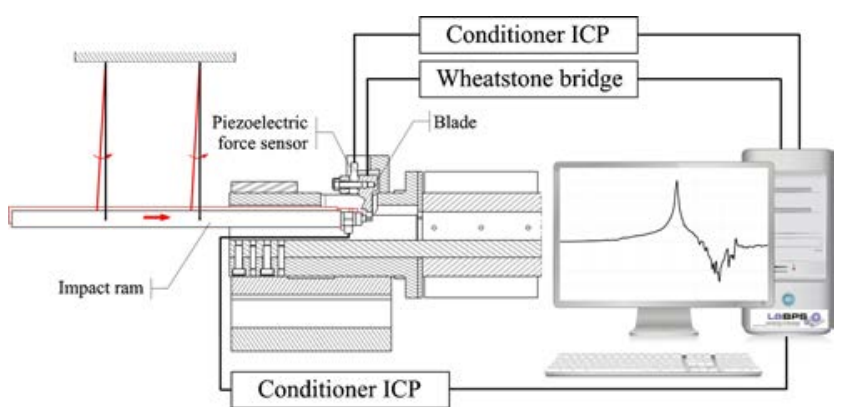

Fig. 7 Experimental set-up for pulse tests

to design a complete set-up which does not have natural frequencies under $10 \mathrm{kHz}$. Consequently, as the dynamic behavior of the mechanical system could not be optimized enough, the traditional way of performing dynamic measurement (restricted to the static approach) was not adapted to this application and another approach had to be found. So, a correction method, detailed in the next section, was implemented to clean up the sensors signals.

\section{Signal Correction}

To virtually enlarge the bandwidth of the measuring system and to eliminate the dynamic and vibratory behavior of the device, the signals were mathematically treated with the method presented by Castro et al. [36] based on the principle of the Frequency Response Function (FRF) [38, 39]. The system response is described by forces or more precisely by output voltages proportional to forces rather than displacements or accelerations. The whole device considered as a linear system is described by equation (1).

$$
\{O(j \omega)\}=[T(j \omega)]\{I(j \omega)\}
$$

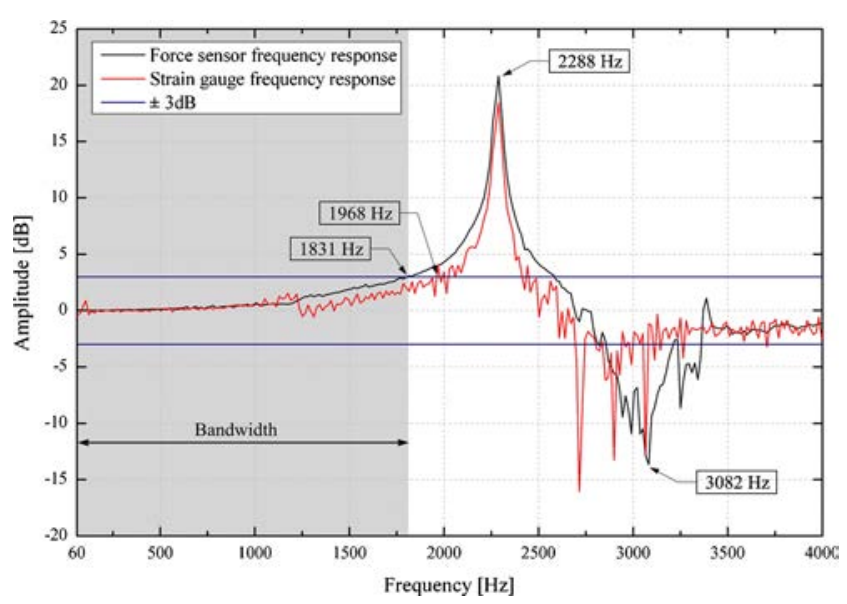

Fig. 8 Dynamic response of the experimental set-up
Transmissibility matrix $[T]$ was determined experimentally. During a calibration step, the device was excited with a white noise and both the excitation force, $\{i(t)\}$, and response signals provided by the sensors, $\{\mathrm{o}(\mathrm{t})\}$, were recorded. Using the modal analysis approach, transmissibility matrix $[T]$ was calculated as the FRF $H_{1}$ (equation (2)), which is the ratio between input-response cross-spectrum $\left(G_{I O}\right)$ and input auto-spectrum $\left(G_{I I}\right)$. Accuracy of the signal correction depended directly on the quality of FRF components which were evaluated thanks to the coherence function $\gamma^{2}$ calculated for each component (equation (4)). A good quality of the FRF corresponds to a coherence function equal to 1 for the whole frequency range.

$$
\begin{aligned}
& H_{1}(j \omega)_{m n}=\frac{G_{I O}(j \omega)}{G_{I I}(j \omega)}=\frac{<O(j \omega)_{m} \cdot \bar{I}(j \omega)_{n}>}{<I(j \omega)_{n} \cdot \bar{I}(j \omega)_{n}>} \\
& H_{2}(j \omega)_{m n}=\frac{G_{O O}(j \omega)}{G_{O I}(j \omega)}=\frac{<O(j \omega)_{m} \cdot \bar{O}(j \omega)_{m}>}{<I(j \omega)_{n} \cdot \bar{O}(j \omega)_{m}>} \\
& \gamma^{2}(j \omega)_{m n}=\frac{H_{1}(j \omega)_{m n}}{H_{2}(j \omega)_{m n}}
\end{aligned}
$$

During the interaction tests, $\{O(j \omega)\}$ was known and $\{I(j \omega)\}$ had to be determined reversing (equation (1)). As the transmissibility matrix was a complex rectangular matrix, it could not be reversed directly. Consequently, the hermitian transpose, defined by equation (5), was necessary to obtain relation (equation (7)).

$[T(j \omega)]^{H}=[\bar{T}(j \omega)]^{T}$

$[H(j \omega)]=\left([T(j \omega)]^{H} \cdot[T(j \omega)]\right)^{-1} \cdot[T(j \omega)]^{H}$

$\{I(j \omega)\}=[H(j \omega)] \cdot\{O(j \omega)\}$

In order to improve their quality, FRF components were calculated by parts. In fact, the experimental set-up was excited with a white noise filtered by a located frequency band (LFB) and the transmissibility matrix sub-components were calculated for the frequency band excited. Then, the FRF matrix components were constructed from the combination of sub-components obtained by all tests. The coherence functions were constructed in the same way. LFB width was a major parameter for the correction method accuracy. Indeed, coherence quality increases and noise quantity decreases when LFB width reduces [36]. However, decreasing LFB width requires the realization of additional measurements. Thus, it was necessary to find a good compromise between the FRF quality and the number of tests. There were a lot of other parameters which had to be carefully fixed because of their influence on the correction functions and their quality. For example, the correction matrix $[H]$ depends on the dynamic behavior of the whole structure supporting the sensor. So it was important to ensure good repeatability of positioning and tightening of the different 


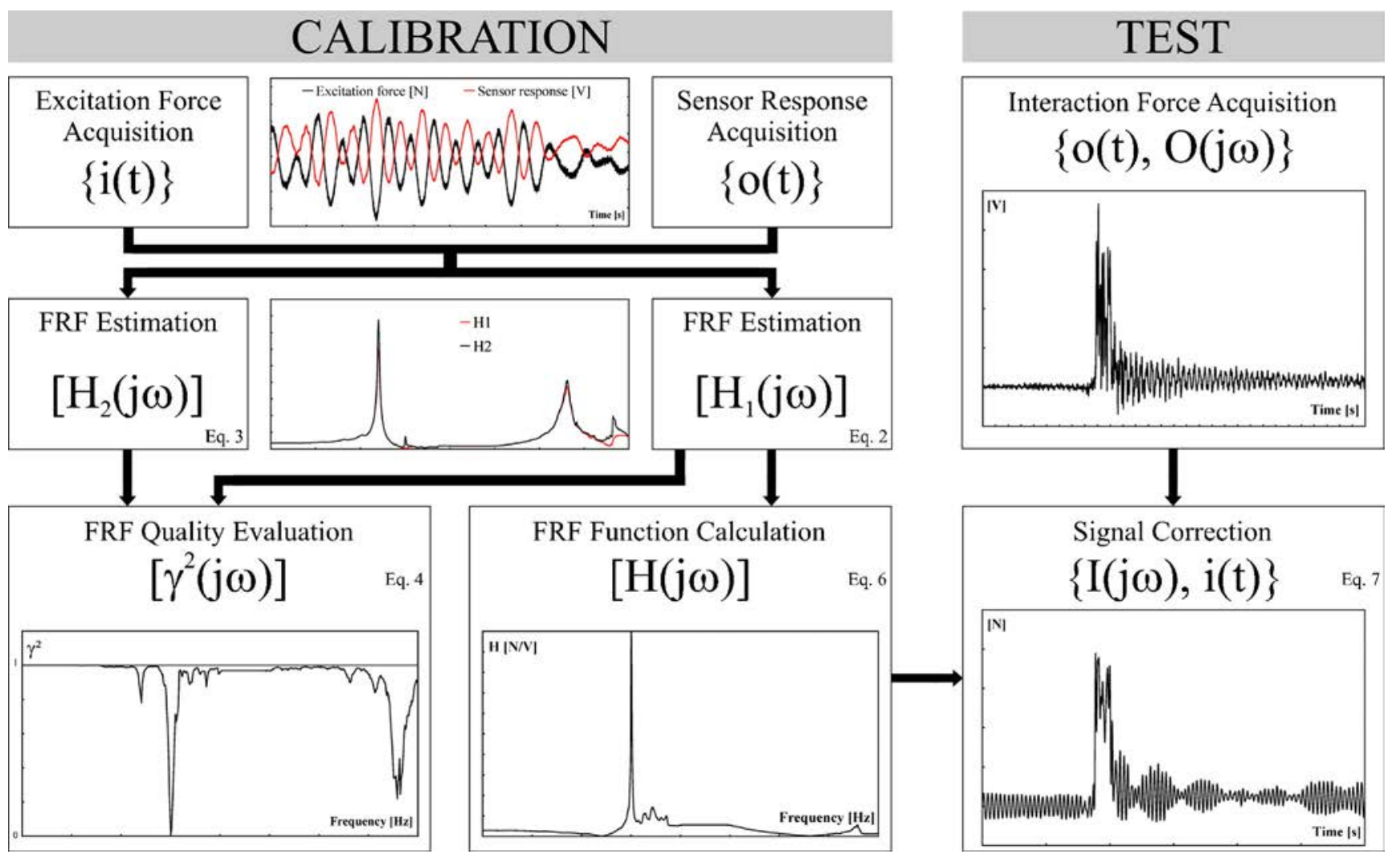

Fig. 9 Diagram of the correction method

parts of the device. The correction procedure is summed up in Fig. 9.

\section{Dynamical Calibration}

In order to correct the signals recorded during the cutting experiments, it was essential to characterize the dynamic behavior of the device and to calculate the transmissibility matrix. Thus, a series of tests was carried out using a known excitation force. The presented configuration of the experimental set-up allowed to measure only the axial force component with two different kinds of sensors. So equation (1) can be written in two unidirectional systems (equation (8)) which makes the comparison between the two measurement technologies possible (equations (9) and (10)).

$\left\{\begin{array}{l}O_{g}(j \omega) \\ O_{p}(j \omega)\end{array}\right\}=\left\{\begin{array}{l}T_{g}(j \omega) \\ T_{p}(j \omega)\end{array}\right\} \cdot I_{a}(j \omega)$

Where: $I_{a}(j \omega)$ : Fourier transformed input signal of axial force imposed on the blade tip $O_{g}(j \omega)$ and $O_{p}(j \omega)$ : Fourier transformed output signals delivered by the strain gauge and by the piezoelectric sensor respectively $T_{g}(j \omega)$ and $T_{p}(j \omega)$ :
Frequency Response Functions of the strain gauge and of the piezoelectric sensor

$I_{a}(j \omega)=\frac{\bar{T}_{g}(j \omega)}{\bar{T}_{g}(j \omega) T_{g}(j \omega)} O_{g}(j \omega)$

$I_{a}(j \omega)=\frac{\bar{T}_{p}(j \omega)}{\bar{T}_{p}(j \omega) T_{p}(j \omega)} O_{p}(j \omega)$

The set-up used during this calibration stage is presented in Fig. 10. The input force was generated by an electromagnetic shaker Bruel \& Kjaer 4809. It imposed a dynamic force on the tip of the blade thanks to a rod. The shaker was

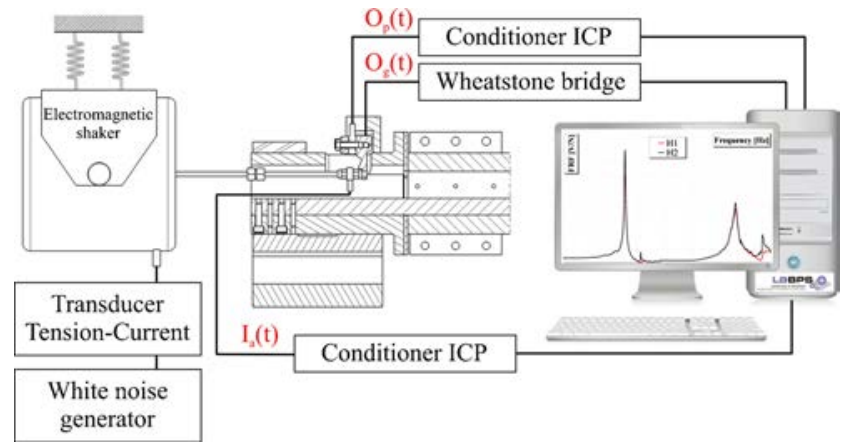

Fig. 10 Experimental set-up for the dynamic calibration 


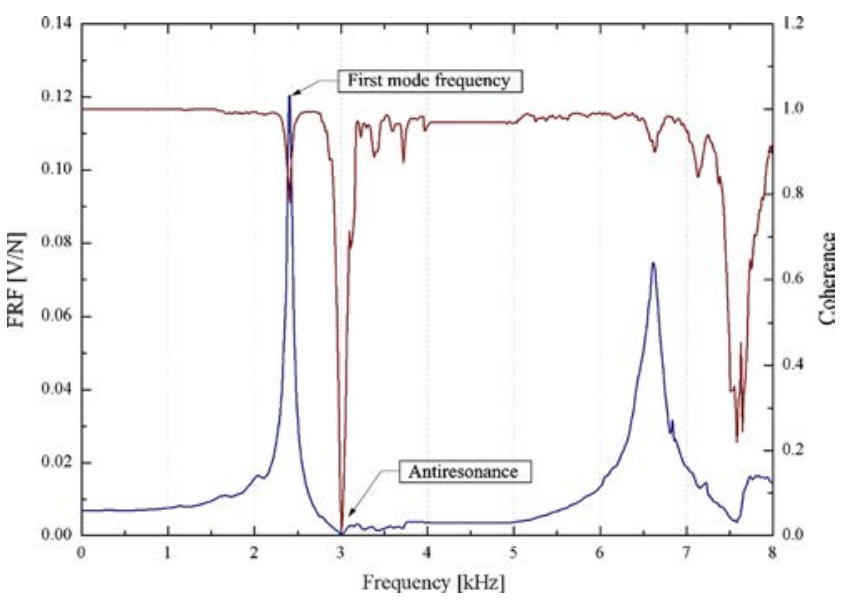

Fig. 11 Piezoelectric force sensor FRF and coherence

freely supported by elastic bands and the rod was designed to be flexible in the directions of the non-excited axis in order to limit undesirable excitations. An analyzer Bruel \& Kjaer 2032 was used to generate white noise in the LFBs and control the shaker. The excitation force imposed by the shaker $\left(i_{a}(t)\right)$ was measured by a piezoelectric force sensor PCB Piezotronic M221B03 and the two outputs $\left(o_{g}(t)\right.$ and $\left.o_{p}(t)\right)$ by the strain gauge and by the piezoelectric force sensor 260A01 respectively. These three signals were recorded with the same acquisition system and with the same parameters as the ones used during the cutting experiments. Modal analysis and calculus of frequency response functions were performed with a special software developed with Mathematica.

FRFs between the reference force sensor and the two sensitive parts of the experimental set-up (strain gauge and piezoelectric force sensor) were obtained between 0 to $8 \mathrm{kHz}$ with a LBF width of $400 \mathrm{~Hz}$.

The coherence function associated with the correction function of the strain gauge signal (not presented here) showed that the FRF quality was not good enough to ensure an accurate correction of the signal recorded by the strain gauge. In a lesser scale and for low frequencies, the FRF of the strain gauge obtained thanks to the pulse tests (Fig. 8) showed the same lack of quality. The sensitivity of the strain gauge was too weak and due to the shaker energy limitation, the excitation force was much smaller than the force that the device was designed to measure. So the amplitude of the response signal during the calibration stage was too low to emerge from electronic noise and the ratio of the system response to the input was incoherent.

As for the piezoelectric force sensor, the results of the calibration provided evidence of good performance (Fig. 11). The FRF between the reference force sensor and piezoelectric force sensor composing the experimental set-up clearly presented resonance and antiresonance peaks and a low frequency dynamic behavior which were in good accordance with the results of the pulse test. However, as the coherence function showed, the FRF accuracy was not perfect for the whole frequency range. More precisely, coherence drops appeared close to the antiresonance peaks. As for the strain gauge FRF, because of the antiresonance, the amplitude of the response signal was too low to not be significantly disturbed by the electronic noise despite the good sensitivity of the force sensor explaining the low quality of the FRF. One way to avoid such coherence drops in future application could be to reduce peak amplitude at antiresonance by increasing the structure dampening by modifying the technical solution of fixing the blade on the sensor. (a)

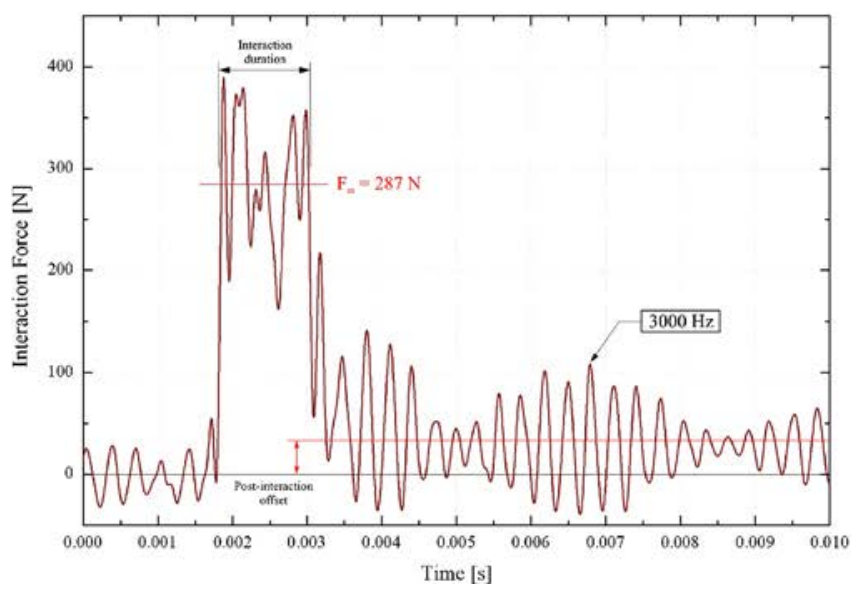

(b)

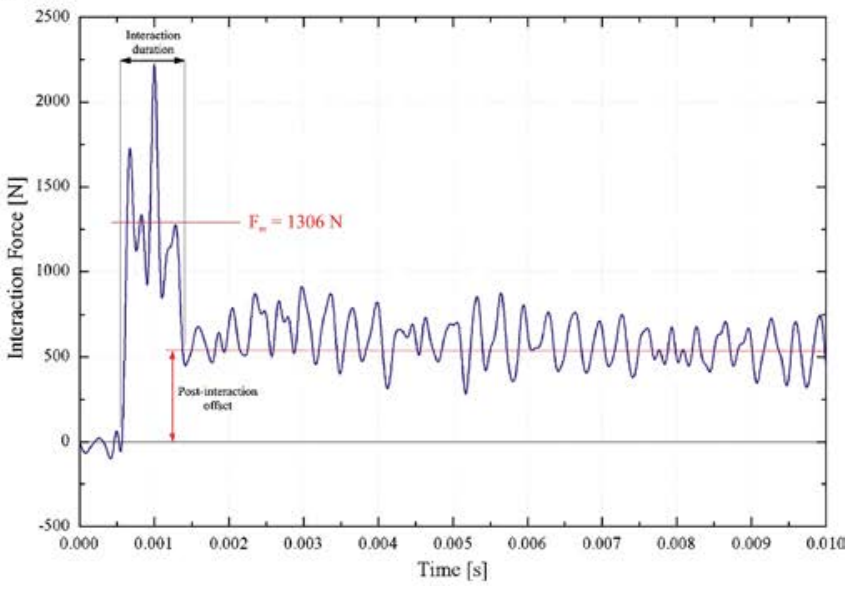

Fig. 12 Typical force signals obtained after post-treatment. (a) Sample M02-Interaction speed: $90 \mathrm{~m} / \mathrm{s}$-Incursion depth: $0.26 \mathrm{~mm}$. (b) Sample M09-Interaction speed: $269 \mathrm{~m} / \mathrm{s}$ - Incursion depth: $0.25 \mathrm{~mm}$ 
Fig. 13 Comparison of raw and corrected signals for two experiments performed with the same conditions. Samples PC01 and $\mathrm{PC} 02$ : Interaction speed: $96 \mathrm{~m} / \mathrm{s}$ - Incursion depth: $0.13 \mathrm{~mm}$

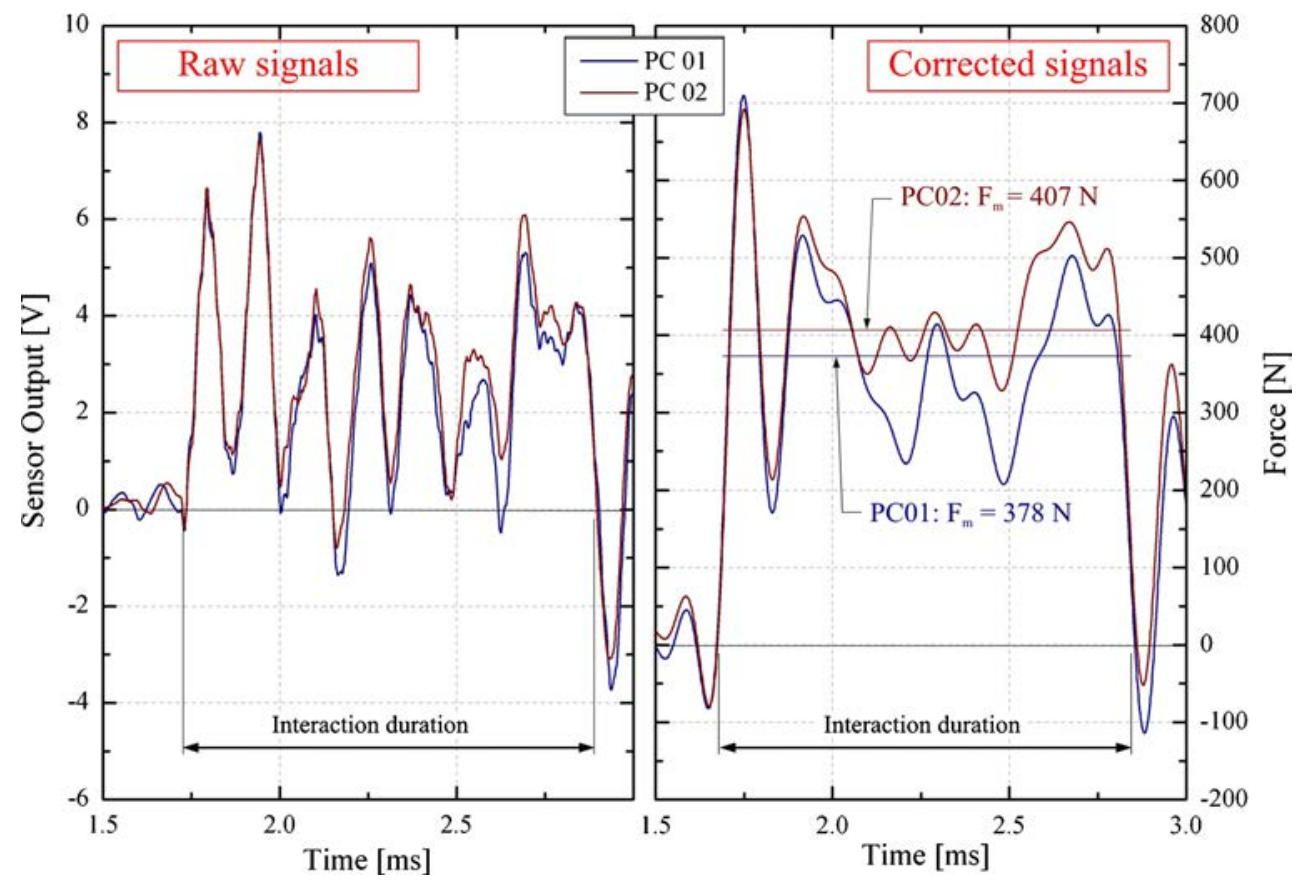

\section{Results \& Discussion}

Measurement and Correction of the Interaction Force

The raw signals recorded all along the interaction process by the piezoelectric force sensor (Fig. 6) were highly perturbed by the dynamic behavior of the set-up even for the lowest interaction velocities. Oscillations visible on the raw force recording were not damped quickly enough to determine precisely the end of interaction or a mean value of the interaction force. As explained previously, conventional static post-treatment was not sufficient to ensure an accurate measurement of the interaction force. Therefore the correction method was applied to obtain the results presented in Fig. 12.

The corrected force signal showed a significant improvement allowing to observe the interaction duration, and to determine mean value of interaction force $F_{m}$. But, corrected signals were disrupted by undamped oscillations before, during and after the process. The correction method

Table 2 Chemical composition of abradable material M601 (Aluminum-silicon alloy and polyester) [15]

\begin{tabular}{|c|c|c|c|c|c|c|}
\hline & \multicolumn{6}{|c|}{ Elements [\%] } \\
\hline & $\mathrm{Al}$ & $\mathrm{Si}$ & $\mathrm{Fe}$ & $\mathrm{C}$ & Impurities & Polyester \\
\hline Min & 51 & 6.5 & I & I & l & The rest \\
\hline Max & 55 & 8.5 & 0.5 & 0.2 & 0.35 & The rest \\
\hline
\end{tabular}

uses Discrete Fourier Transform which allows to approximate a discontinuous non-periodic function with a sum of continuous periodic functions. It can generate a mathematical phenomenon of discontinuity amplification which creates damped oscillations in the vicinity of the discontinuity. So, oscillations were expected at the beginning and at the end of interaction. However oscillations observed on the post-treated force signal had great amplitude and persisted long after the interaction without being damped. So they could not have been due to this phenomenon. In addition, the frequency of these oscillations calculated by spectral analysis corresponded exactly to the coherence drop frequency observed on the FRF used for the dynamic correction. The authors concluded that they were mathematical artifacts due to the localized low quality of the correction function. The only solution to eliminate this artifact will be to improve the quality of the FRF by modifying the experimental set-up in order to reduce the peak amplitude at the antiresonance frequency. However, despite these artifacts, it is possible to calculate a significant mean value of interaction force.

An offset was clearly observable after the interaction process on the piezoelectric force sensor raw signal and on the corrected signal, see Fig. 12(b). It increased with the interaction velocity and therefore was linked to the launching pressure which applied a force on the blade tip after the projectile passage. Its value was highly inferior to the interaction force. So, it did not pertubate the measurement or the interpretation of the corrected signal. 
The strain gauge raw signal was less dynamically perturbed than the piezoelectric force sensor at least for the experiments performed with low interaction velocity (inferior to $100 \mathrm{~m} / \mathrm{s}$ ). For these experiments, the interaction duration was clearly visible and the force varied around a mean value. This mean value was coherent with the one obtained by correcting the piezoelectric force sensor signal. The elastic deformation rate measured by the strain gauge was too low to ensure good measurement precision. Indeed, electronic noise present on the recorded signals represented almost $30 \%$ of the signal amplitude. Furthermore, the gauge signal was not dynamically corrected because of the very low quality of the correction function. So low deformation rate is a major problem which can be solved in two ways. A first solution could consist of modifying the blade geometry in order to increase its deformation, but it is not recommended. It would reduce the blade stiffness and increase the displacement of the blade tip as well as the variation of the incursion depth. A second way to achieve a greater sensitivity could be to replace the traditional strain gauge by a semiconductor strain gauge. However, the piezoelectric force sensor seemed more appropriate for future applications.

Finally, three cutting experiments were performed with polycarbonate samples in the same experimental conditions in order to study the repeatability of the process and the measurement system. The raw signals of the piezoelectric force sensor for the experiments PC01 and PC02 (Fig. 13) could almost have been superimposed demonstrating the good repeatability of the set-up. The slight differences were amplified by the dynamic correction explaining the two mean interaction force values.
Table 4 Chemical composition of steel 42CrMo4

\begin{tabular}{|c|c|c|c|c|c|c|c|}
\hline & \multicolumn{7}{|c|}{ Elements [\%] } \\
\hline & $\mathrm{C}$ & $\mathrm{Cr}$ & Mo & $\mathrm{Mn}$ & $\mathrm{Si}$ & S & $\mathrm{P}$ \\
\hline Min & 0.38 & 0.9 & 0.15 & 0.6 & I & I & / \\
\hline Max & 0.45 & 1.2 & 0.25 & 0.9 & 0.4 & 0.035 & 0.025 \\
\hline
\end{tabular}

\section{Abradable Material M601/ Steel 42CrMo4 Interaction}

The first purpose of this project was to experimentally study blade-casing contacts phenomena and to extend the knowledge of the material behavior of a given abradable material under extreme conditions. A simplified approach where only orthogonal cutting conditions are investigated was carried on thanks to the experimental technique presented in the previous sections. New experimental data on the material behavior of M601 in high speed orthogonal cutting conditions have been obtained and those obtained for low interaction velocities have been compared to the data available in the literature.

The chosen abradable material was the M601, an abradable material developed by Sulzer Metco whose the chemical composition is presented in Table 2. As shown in Table 3, a set of cutting experiments on abradable material M601 were performed for a range of interaction velocities varying from $60 \mathrm{~m} / \mathrm{s}$ to $270 \mathrm{~m} / \mathrm{s}$ and of incursion depths from $0.13 \mathrm{~mm}$ to $0.35 \mathrm{~mm}$. The blade was made of steel $42 \mathrm{CrMo} 4$ (Table 4). Its edge was regularly sharpened to maintain its radius at $25 \mu \mathrm{m}$. The tested materials couple
Table 3 Testing conditions and experimental results

\begin{tabular}{llllll}
\hline & & Interaction velocity & \multicolumn{2}{l}{ Incursion depth } & \multirow{2}{*}{ Interaction force } \\
\cline { 5 - 6 } Tests & Sample & $V_{i}$ & $t_{1}$ & $\Delta t_{1}$ & \multirow{2}{*}{$F_{m}$} \\
$\mathrm{~N}^{\circ}$ & Materials & {$[\mathrm{m} / \mathrm{s}]$} & {$[\mathrm{mm}]$} & {$[\mathrm{mm}]$} & {$[\mathrm{N}]$} \\
\hline PC01 & Polycarbonate & 96 & 0.13 & 0.042 & 378 \\
PC02 & Polycarbonate & 96 & 0.12 & 0.032 & 407 \\
PC03 & Polycarbonate & 97 & 0.18 & 0.048 & 422 \\
PC04 & Polycarbonate & 123 & $\backslash$ & $\backslash$ & 524 \\
PC05 & Polycarbonate & 184 & 0.18 & 0.043 & 873 \\
M01 & M601 & 61 & 0.30 & $\backslash$ & 230 \\
M02 & M601 & 90 & 0.26 & 0.040 & 287 \\
M03 & M601 & 90 & 0.35 & 0.053 & 362 \\
M04 & M601 & 118 & 0.13 & 0.032 & 411 \\
M05 & M601 & 153 & $\backslash$ & $\backslash$ & 436 \\
M06 & M601 & 191 & 0.26 & 0.049 & 740 \\
M07 & M601 & 226 & 0.28 & 0.060 & 1060 \\
M08 & M601 & 228 & 0.15 & 0.022 & 778 \\
M09 & M601 & 269 & 0.25 & 0.069 & 1306 \\
\hline
\end{tabular}


(M601/42CrMo4) is not the same as the one found in the engines compressors (M601/TA6V). For this first approach, the hypothesis was made that, as the dynamical behavior of the blade is not considered, the material of the blade has a insignificant influence on the interaction force in regard of the mechanical and geometrical conditions of the interaction.

Figure 14 presents the evolution of the mean interaction force per unit of width $F_{m} / W_{s}$ generated during interaction process as a function of the interaction velocity $V_{i}$ and the incursion depth $t_{1}$. Mean interaction force per unit of width values for the low interaction velocity experiments (inferior to $100 \mathrm{~m} / \mathrm{s}$ ) with a blade edge radius of $25 \mu \mathrm{m}$ were in good agreement with data available in the literature, especially with those proposed by Sutter et al. [15].

Figure 14 shows also that the interaction force increased with the interaction speed and the incursion depth. More precisely, the relation between the interaction force $F_{m}$ and the interaction velocity $V_{i}$ did not seem linear as the data available in the litterature [15] suggest. Indeed, the relation between the interaction force $F_{m}$, the interaction velocity $V_{i}$ and the incursion depth $t_{1}$ can be described by the empirical law (equation (11)).

$F_{m}\left(t_{1}, V_{i}\right)=\left(a . t_{1}+b\right) e^{c . V_{i}}$

These results clearly showed a viscous behavior of the abradable material Metco M601 and was consistent with a visco-plastic behavior such as the one describes by a model of Norton. Furthermore, it is interesting to note that this nonlinear behavior is very similar to the one described by Yi et al. [6]. The authors, who performed erosion tests, show that for law impact angle, erosion can be assimilate to microcutting and that the erosion rate depends on the impact velocity following a power law for low impact angle.

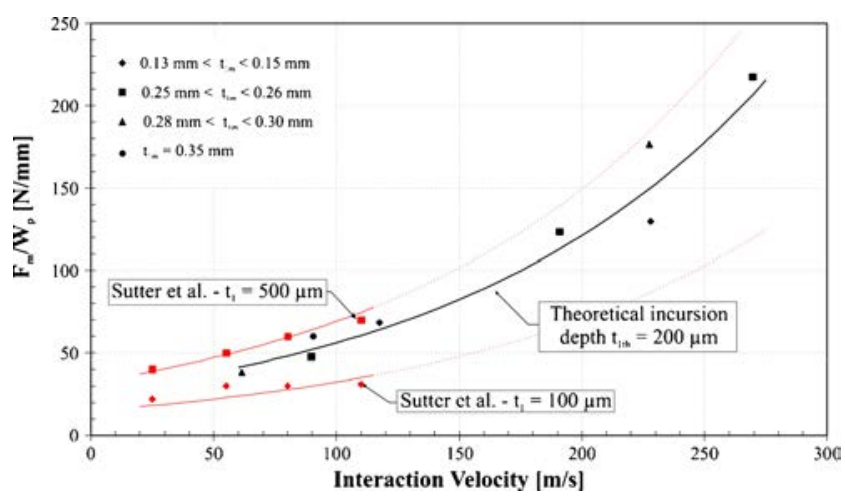

Fig. 14 Interaction force as a function of the interaction velocity and the incursion depth for abradable material M601 in orthogonal cutting conditions for a blade edge radius close to $0.001 \mathrm{~mm}$

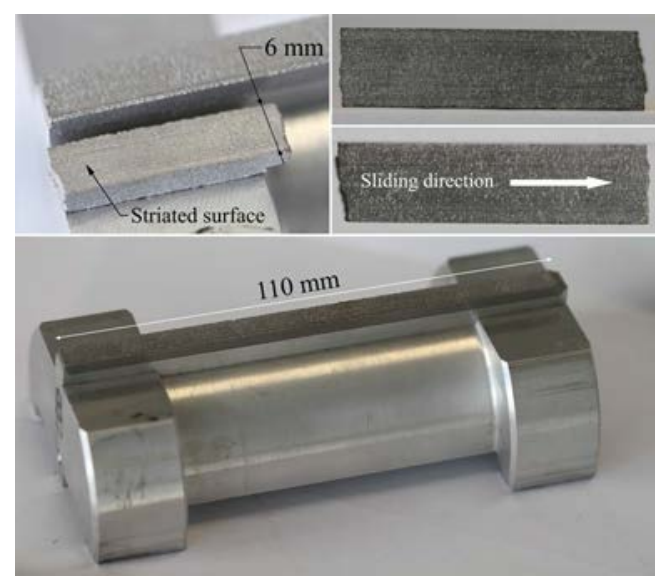

Fig. 15 Photographs of an abradable sample after interaction

Finally, the powder of M601 found in the receiving tank as well as the observation of the post-experiment surfaces of the M601 samples gave evidence of two wear mechanisms described by Borel [7]: cutting with brittle rupture of the abradable material and plastic deformation. Indeed the created surfaces (Fig. 15) were striated and showed traces of smearing. These two elements are representative of the plastic deformation mechanism.

\section{Conclusion}

An experimental technique has been designed to study blade-casing contact phenomena. These interactions have been assimilated to high speed orthogonal cutting and the interaction force has been measured.

A correction method based on modal analysis principles has been developed in order to reduce the influence of the sensor dynamic behavior on the measured interaction force. This correction method allowed to precisely measure the mean force generated during interactions lasting less than $400 \mu s$. However, this correction method remains to be optimized to permit to study the evolution of the force during the interaction. It will require to suppress the artifacts appearing during the correction and to improve the correction function quality. In order to do that, a modification of the experimental set-up - and consequently its dynamical behavior-is unavoidable. The device structural damping has to be increased by adding a damper to reduce the peak amplitude at the antiresonance frequency.

The experiments performed to characterize the abradable material Metco M601 showed a viscous behavior of the 
M601 and revealed a non-linear relation existing between the mean interaction force and the interaction velocity. This relation as well as the interaction force values measured for the experiments performed with low interaction velocities were in good agreement with the data available in the literature.

Finally, to extend the understanding of the blade-casing contact phenomena, it will be important to investigate the material behavior under experimental conditions more close to the real functioning conditions. This means simulating oblique cutting process for the highest interaction velocities $(500 \mathrm{~m} / \mathrm{s})$ and the operating temperature $\left(300^{\circ} \mathrm{C}\right)$.

Acknowledgments This work takes place in the framework of the MAIA mechanical research and technology program sponsored by SNECMA of SAFRAN Group. The authors are grateful for the financial support to develop this project. They would also like to acknowledge Mr. David Stinger, engineer at the National Engineering School of Metz (E.N.I.M.), for his contribution to the device design.

\section{References}

1. DeMasi-Marcin JT, Gupta DK (1994) Protective coatings in the gas turbine engine. Surf Coatings Technol 68-69:1-9

2. Dalzell WJ, Sanders SA, Crawford GL, Walden FC, Woodard WJ (2002) Abradable seal with improved properties. Seal Technol 2002(8):14-15

3. Dorfman M, Erning U, Mallon J (2002) Gas turbines use abradable coatings for clearance-control seals. Seal Technol 97:7-8

4. Faraoun HI, Grosdidier T, Seichepine JL, Goran D, Aourag H, Coddet C, Zwick J, Hopkins N (2006) Improvement of thermally sprayed abradable coating by microstructure control. Surf Coatings Technol 201:2303-2312

5. Bounazef M, Guessasma S, Ait Saadi B (2004) The wear, deterioration and transformation phenomena of abradable Bn-SiAlcoating bounding organic element, caused by the friction between the blades and the turbine casing. Mater Lett 58:3375-3380

6. Yi M, Huang B, He J (2002) Erosion wear behaviour and model of abradable seal coating. Wear 252:9-15

7. Borel MO, Nicoll AR, Schlapfer HW, Schmid RK (1989) The wear mechanisms occuring in abradable seals of gas turbines. Surf Coatings Technol 39:117-126

8. Johnston RE, Evans WJ (2007) Freestanding abradable coating manufacture and tensile test development. Surf Coatings Technol 202:725-729

9. Faraoun HI (2005) Modelisation des proprietes thermomecaniques des materiaux abradables. PhD thesis, Universite de FrancheComte-Universite de Technologie de Belfort-Montbeliard

10. Faraoun HI, Seichepine JL, Coddet C, Aourag H, Zwick J, Hopkins N, Sporer D, Hertter M (2006) Modelling route for abradable coatings. Surf Coatings Technol 200:6578-6582

11. Bounazef M, Guessasma S, Adda Bedia EA (2007) Blade protection and efficiency preservation of a turbine by a sacrificial material coating. Adv Powder Technol 18(2):123-133

12. Rathmann U, Olmes S, Simeon A (2007) Sealing TechnologyRub test Rig For Abrasive/Abradable Systems ASME Turbo Expo (Proceedings)
13. Steinke T, Mauer G, Vaßen R, Stöver D, Roth-Fagaraseanu D, Hancock M (2010) Process design and monitoring for plasma sprayed abradable coatings. J Therm Spray Tech 19(4):756764

14. Yi M, He J, Huang B, Zhou H (1999) Friction and wear behaviour and abradability of abradable seal coating. Wear 231:47-53

15. Sutter G, Philippon S, Garcin F (2006) Dynamic analysis of the interaction between an abradable material and a titanium alloy. Wear 261:686-692

16. Puerta Velasquez JD (2007) Etude des copeaux et de l'integrite de surface en usinage grande vitesse de l'alliage de titane ta6v. PhD thesis, Universite Paul Verlaine-Metz

17. Faure L, Philippon S, Lodygowski A, Voyiadjis GZ, Rusinek A, Chevrier P, Dossou E (2009) Design of a dynamometer capable of capturing the dry friction force in dynamic conditions. Workshop in memory of J R Klepaczo, Metz 189-197

18. Philippon S, Voyiadjis GZ, Faure L, Lodygowski A, Rusinek A, Chevrier P, Dossou E (2011) A device enhancement for the dry sliding friction coefficient measurement between steel 1080 and vascomax with respect to surface roughness changes. Exp Mech 51:337-358

19. Guegan P, Yosra G, Poitou A (2005) Analyse experimentale de la coupe orthogonale sur dispositif equipe d'une barre d'hopkinson et de cameras videos rapides. 17eme Congres Français de Mecanique

20. Rajagopalan S, Prakash V (1999) A modified torsional kolsky bar for investigating dynamic friction. Exp Mech 39:295-303

21. Espinosa H, Patanella A, Fischer M (2000) Dynamic friction measurements at sliding velocities representative of high-speed machining processes. J Tribol 122:834-848

22. Philippon S, Sutter G, Molinari A (2004) An experimental study of friction at high sliding velocities. Wear 257:777-784

23. Lodygowski A, Faure L, Voyiadjis G, Philippon S (2011) Dry sliding friction experiments at elevated velocities. Strain 47(s2):436453

24. Chevrier P (1998) Mecanique et mesomecanique de l'ecaillageessais experimentaux et critere de rupture-etude d'un alliage d'aluminium et d'un acier de blindage. PhD thesis, Universite de Metz, France

25. Jin WL, Venuvinod PK, Wang X (1995) An optical fibre sensor based cutting force measuring device. Int J Mach Tool Manuf 35:877-883

26. Seker U, Kurt A, Ciftci I (2002) Design and construction of a dynamometer for measurement of cutting forces during machining with linear motion. Mater Des 23:355-360

27. Gunay M, Seker U, Sur G (2006) Design and construction of a dynamometer to evaluate the influence of cutting tool rake angle on cutting forces. Mater Des 27:1097-1101

28. Karabay S (2007) Analysis of drill dynamometer with octagonal ring type transducers for monitoring of cutting forces in drilling and allied process. Mater Des 28:673-685

29. Karabay S (2007) Performance testing of a constructed drilling dynamometer by deriving empirical equations for drill torque and thrust on SAE 1020 steel. Mater Des 28:17801793

30. Korkut I (2003) A dynamometer design and its construction for milling operation. Mater Des 24:631-637

31. Yaldiz S, Unsacar F (2006) A dynamometer design for measurement the cutting forces on turning. Measurement 39:80-89

32. Yaldiz S, Unsacar F, Saglam H, Isik H (2007) Design, development and testing of a four component milling dynamometer for the measurement of cutting force and torque. Mech Syst Signal Process 21:1499-1511 
33. Totis G, Wirtz G, Sortino M, Veselovac D, Kuljanic E, Klocke F (2010) Development of a dynamometer for measuring individual cutting edge forces in face milling. Mech Syst Signal Process 24:1844-1857

34. Oraby SE, Hayhurst DR (1990) High-capacity compact threecomponent cutting force dynamometer. Int J Mach Tool Manuf 30:549-559

35. Kim JD, Kim DS (1997) Development of a combined-type tool dynamometer with a piezo-film accelerometer for an ultraprecision lathe. J Mater Proc Technol 71:360-366
36. Castro Martinez LR (2006) Identification des sources de vibration en usinage. Etude experimentale et numerique. $\mathrm{PhD}$ thesis, Universite Paul Verlaine-Metz

37. Tounsi N, Otho A (2000) Identification of machine-toolworkpiece system dynamics. Int J Mach Tool Manuf 40:13671384

38. Ewins DJ (2008) Modal testing: theory, practice and application, 2nd edn. Research Studies Press, Hertfordshire

39. Harris CM, Crede CE (1976) Shocs and vibration handbook, 2nd edn. McGraw Hill Higher Education, New York 